\title{
LA CIUDAD COMO POSIBILITADORA DE INCLUSIÓN Y COMO FACILITADORA DE EXPULSIÓN
}

\section{THE CITY AS A FACILITATOR OF INCLUSION AND AS A FACILITATOR OF EXPULSION}

Alejandro Klein ${ }^{1}$

\section{RESUMEN}

El objetivo de este trabajo es plantear una reflexión sobre algunos dilemas por los que atraviesa el formato social y cultural de la ciudad, especialmente en torno a los pares: inclusión-exclusión; ciudadanía-violencia. Se propone un desarrollo de estos dilemas urbanos y las consecuencias que los mismos implican.

El estudio fue realizado a partir de una revisión bibliográfica de diversos autores que trabajan el tema con especial énfasis en autores latinoamericanos.

En las conclusiones se indica que el estado en que se encuentra esta área de investigación revela algunas contradicciones, aunque también existe consenso en torno a la necesidad de replantear el lugar de la ciudad en torno a la discusión sobre ciudadanía, democracia participativa y alternativas frente al neoliberalismo. Se hace necesario plantear investigaciones a más largo plazo que puedan dar cuenta de cómo se van desenvolviendo estos procesos.

Por último, se pone especial énfasis en la discusión acerca del significado de la violencia, haciéndose énfasis en el tema del miedo cotidiano, la inseguridad urbana y el déficit de las figuras dialógicas. -

\section{PALABRAS CLAVE}

ciudad, integración, expulsión, violencia, ciudadanía

\footnotetext{
${ }_{1}$ Profesor Investigador de la Universidad de Guanajuato, Associate Fellow- Oxford Institute of Population Ageing. Universidad de Guanajuato - México. E-mail: alejandroklein@hotmail.com
} 


\section{ABSTRACT}

The objective of this paper is to propose a reflection about some dilemmas that the social and cultural format of the city goes through, especially around peers: inclusion-exclusion; citizenshipviolence. It proposes a development of these urban dilemmas and the consequences that they imply.

The study was conducted based on a bibliographic review of several authors who work on the subject with special emphasis on Latin American authors.

The conclusions indicate that the state in which this area of research is located reveals some contradictions, although there is also consensus around the need to rethink the place of the city around the discussion on citizenship, participatory democracy and alternatives to the neoliberalism. It is necessary to propose longer-term research that can focus how these processes unfold.

Finally, special emphasis is placed on the discussion about the meaning of violence, emphasizing the theme of daily fear, urban insecurity and the deficit of dialogical figures. -

\section{KEYWORDS}

city, integration, expulsion, violence, citizenship

\section{INTRODUCCIÓN}

En todo el mundo y dentro de una tendencia cada vez más creciente, la constitución de lo urbano se asienta como un espacio geográfico, económico, cultural, social e identitario de importancia fundamental. Se estima que más de la mitad de la población mundial ya está urbanizada y una quinta parte vive en ciudades de uno a cinco millones de habitantes, y en este sentido se habla de "metrópolis" (Gavidia, 1994; Ingram, 1998) las que mantienen una enorme importancia económica, social y cultural (Negrón, 1998).

La ciudad se ha tornado así en un punto de reflexión ineludible dentro de las ciencias sociales. Si en algún momento se la conceptualizó como generadora de soluciones frente a situaciones de vivienda, hábitat o trabajo, ahora se la vivencia, igualmente como generadora de problemas. Desde el imaginario social, si antes la ciudad era la promesa de igualdad, desarrollo y oportunidades, hoy es un foco de diversas problemáticas, generándose la sensación de que la misma es un "mal necesario", solo deseable para trabajar pero no para vivir, vacacionar o sostener redes sociales. 
La ciudad se vuelve así en un malestar, tanto como un síntoma. Aglutina tanto como expresa y resignifica una variedad heterogénea de problemáticas sociales. Algunos visibles (la inseguridad, la pobreza, la dificultad de concretar servicios públicos eficaces) y otros que se invisibilizan (por ejemplo, el tema del miedo confundido -probablemente de forma errónea- con el de la “inseguridad" lo que se retomará en las conclusiones).

En este trabajo no se podrá analizar con la debida profundidad todas estas dimensiones críticas, pero se intentará aportar algunos elementos para un debate en torno a cómo la ciudad en tanto generadora de cultura propicia condiciones de integración y/o de exclusión. No se pretende una visión cabal del tema, pero sí alcanzar alguna perspectiva de la significación de la matriz y la cultura urbana contemporánea en relación a dichos ejes de análisis, manteniendo especial referencia al tema del miedo y la violencia, temas que parecen preocupar cada vez más a los autores, la población y los medios de comunicación.

\section{DOS FORMAS DE PRESENTACIÓN DE LO URBANO}

En el estudio de la cultura urbana parecen presentarse dos grandes vertientes, que no pocas veces se contradicen o se enfrentan entre sí. Por un lado, al hablarse de "ciudad", se invoca un "proyecto" de ciudad, una idea de un espacio amplio, confiable y englobante donde todos los habitantes tendrían un lugar preestablecido, garantizado. Por otro, y antinómicamente, la ciudad se erige en un espacio simbólico de segregación y rechazo, de privilegios y dominación, miedo e inseguridad (MARGULIS, 1997).

Estas dos formas de presentación de la urbanidad (aunque simplificando matices y obviando otros factores) lleva a sugerir dos modalidades de esta cultura. Se denominará a la primera como posibilitadora de inclusión y a la segunda como facilitadora de expulsión

\section{LA CULTURA URBANA COMO MATRIZ INTEGRADORA.}

Desde este modelo integrador se despliega un proyecto y una posibilidad de integración, como plena "invitación" a la participación y al desarrollo del "furor" cívico. Es, de alguna manera, el desafío y la profundización de la ciudadanía presente desde el modelo keynesiano (KLEIN, 2006). La ciudad se concibe desde y con sus habitantes. Y la ciudadanía, como formando parte de la visión de un vínculo individuo-sociedad, en términos de gestación de una promesa que asegura un porvenir y un proyecto tanto social como individual (ídem). Esta "promesa" (COUTINHO, 2000) al 
enunciar una serie de "instrumentos" efectivos de ciudadanización y progreso social (como el trabajo y la educación ) asegura a sus habitantes (más o menos plenamente) un lugar en la sociedad urbana, como forma de contrato social vigente.

Este consenso cultural de una humanidad plena a la que se aplican a todos por igual, sistemas abstractos, cultura y leyes, configura un sistema de vida que se podría denominar de "sociedad amplia", (KLEIN, 2006) la que implica la posibilidad de que todos los seres humanos están integrados o son integrables a la sociedad por los procesos de ciudadanización. Su correlato a nivel urbano es presentar a la ciudad como agente de transformación, dentro de una empresa colectiva (es decir unificante) que busca, al decir de Jaime Lerner, ex-alcalde de Curitiba (Brasil): "la realización de un sueño colectivo (....). La ciudad tiene que concebirse como una estructura abierta, como un organismo vivo que ofrece espacio, convivencia y oportunidades para todos" (BOISTEAU, 2007:2830).

La ciudad se torna así un mundo posible de gente que desea vivir, cuidarse a sí misma (FOUCAULT, 1988, 2012) y ser cuidada. Crecer, tanto como experimentar cosas nuevas. La ciudadanización urbanizadora funda así un marco de expectativa razonable de trabajo, bienestar y vida digna, revelando una estructura de cuidado y de amparo en términos biopolíticos (FOUCAULT, 1984,2012).

La cultura urbana aparece así como organizadora eficaz del entorno material y social (GIDDENS, 1997), expresión de un sentimiento de confianza, seguridad y continentación. Es, en tal sentido, una cultura erótica, en tanto expresa una actividad que plantea como desafío, la posibilidad de integrar permanente a sus habitantes (LAPLANCHE-PONTALIS 1981). Matriz que incluye además el consenso de un gran todo unificador (AULAGNIER, 1975), un sistema de interrelación recíproca sociedad -subjetividad (FREUD, 1931), institucionalidad sólida (LEWKOWICZ, 2004) y figuras de mediación (KAËS, 1993) entre la ciudad y sus habitantes, dentro de un contrato social urbano.

Este contrato social se legitima (NISBET, 1996) al estar acompañado de la noción de reciprocidad sociedad- sujeto, surgiendo la noción de: "comunidad de todos los ciudadanos" (ARIÈS-DUBY, 1990: 48), que postula que la sociedad está integrada por individuos, que en tanto seres autónomos (CASTEL, 1997), son detentores de derechos a los que la comunidad defiende (PACHECO, 2000), como el derecho a protegerse de la violencia (KAËS, 1993), tanto como aceptan la necesidad de renuncia para obtener una compensación social (FREUD, 1931).

Cada persona se continúa en la ciudad y la ciudad se continúa en sus ciudadanos, a los que “invita” a la participación. La visión de la sociedad como un 'todo' invoca grandes conjuntos donde 
lo englobante permite que todos posean un lugar diferenciado. Lo integrador, nucleador y optimista (FISHER, 1996) hace que la sociedad aparezca armoniosa ${ }^{2}$ y "con tejido social más unido" (PRETECEILLE, 1996: 22). Teresa Pires do Rio Caldeira (2000) describe prototípicamente este modelo urbano- histórico, donde las clases sociales 'parecían' poder convivir e interrelacionarse.

Por esta cultura del diálogo el otro es alguien reconocible y con el cual se puede compartir y discutir de forma razonable, antes que recurrir a la violencia o la hostilidad (BECK, 1997), generando con ese "amigo" - "vecino" cooperación e intercambio dentro de una "conciencia de contingencia" por la que todos son y tienen derecho a ser distintos, consolidándose un ideal de lo fraternal que tiene que ver con la tolerancia, la diversidad y la solidaridad (BAUMAN, 1999). Implica además, al mismo tiempo, ser percibido por la sociedad como un interlocutor válido, alguien que tiene o desea tener, un lugar de integración en la misma (DUSCHATZKY, 2002).

Esta importancia estructurante de lo fraterno a nivel social y sujetivo ha sido destacado por Kancyper $(1992,1997)$ (complejo fraterno), Birman (2001) (valores de alteridad, reciprocidad y reconocimiento como forma no-narcisista de aceptar al otro), Kehl (2000) (asunción de la incompletud en torno a la ética y la responsabilidad) y Ruiz (2000) (responsabilización por el sufrimiento del otro) y tiene que ver probablemente con las figuras de la solidaridad vincular y lo solidario social.

Desde los estudios urbanos se habla de un capital social, que: "se refiere a aspectos de la organización social tales como redes, normas y lazos de confianza que facilitan la coordinación y cooperación para beneficios mutuos" (PUTNAM, 1993: 1), lo que tiene como implícito un sentido de "confianza" en relación a instituciones fuertes y garantes de la ley y de marcos judiciales de regulación.

Su garante es la ley y ése parece ser uno de los fundamentos esenciales del contrato social urbano: la existencia indudable de garantías. La ciudad es "tierra simbólica" y desde allí se insiste en los grados de comunicación representados por la calle, los paseos, las plazas recorridas y habitadas por todos los ciudadanos. Se comparte el orgullo de ser ciudadano, de ser "iluminado" por el "brillo" de las leyes (ARAUJO, 2002), por formar parte de la dinámica social ocupada por instituciones justas y soberanas dentro de una ciudad "viva" y en transformación.

\footnotetext{
${ }^{2}$ Lo que no descarta la existencia de conflictos sociales y luchas de clases
} 


\section{LA CIUDAD COMO CULTURA DE RENOVACIÓN LOCAL FRENTE A LA GLOBALIZACIÓN}

Una expresión de las ciudades en proceso de transformación y de conservación del capital de ciudadanía y participación, refiere a su ubicación como motores de desarrollo económico (FISHER, 1996). Concepto que se va gestando desde el año 1989, y llega en el año 1993 al reconocimiento en Maastricht, de los gobiernos locales como una red institucional. Las ciudades europeas son llamadas ahora "las multinacionales europeas" (ídem). Esta posición se asentó durante los procesos de crisis neoliberales, lo que: "provocó la reacción conjunta del gobierno local y de los principales agentes económicos, llevándolos a buscar la transformación de la infra-estructura urbana" (FISHER, 1996: 82).

Se presentó así como necesario que uno de los cambios deseables e imprescindibles de la ciudad, implicara la reorganización de procesos locales frente a lo global, indicándose que: "Por su tamaño y su estructura económica, compleja y diversificada, por el nivel de su infraestructura ellas [las ciudades] constituyen puntos nodales primordiales de la globalización económica " (PRETECEILLE, 1996: 33). La ciudad aunque no aparece como responsable de crear los efectos negativos de la globalización (o el neoliberalismo, habría que precisar) se vuelve, desde esta concepción, por lo menos responsable de buscar soluciones frente a situaciones adversas: "lo que se ha reconocido es la necesidad de tratar la problemática social (empleo, pobreza, integración socio-cultural) a nivel local" (PRETECEILLE, 1996: 79). Se indica en tal sentido que en la época de la recesión económica de los años '70 fueron las ciudades las que hicieron un esfuerzo por atraer inversiones, generar empleo y renovar la base productiva de la ciudad (FISHER, 1996).

Este principio 'protector' o compensador de lo local frente a lo global se anuda a la idea de un movimiento de renovación urbano como desafío de cultura cívica y de protección ciudadana, aspectos que van más allá de lo económico y que parecen asociarse a una renovación del contrato urbano integrador:

Las grandes ciudades deben enfrentar cinco tipos de desafíos: nueva base económica, infra-estructura urbana, cualidad de vida, integración social y gobernabilidad. Solamente generando la capacidad de dirigirlos podrán ser competitivas, insertarse en los espacios económicos globales y garantizar a su población un bienestar mínimo, necesario para la consolidación de la convivencia democrática (BORJA, 1997: 82).

Corroborando esta perspectiva se afirma, por otro lado, que en el siglo XXI el progreso económico y el bienestar social y la integración cultural de los pueblos se verificará en las ciudades 
(PRETECEILLE, 1996), en relación a su capacidad por adaptarse a "las nuevas formas de urbanización" (ÍDEM: 35).

Esta dimensión de cómo se percibe y conceptualiza el lugar de la ciudad, se correlaciona simultáneamente con la búsqueda de profundización del proceso democrático a nivel urbano, revalorizando especialmente la dimensión de democracia deliberativa, unida a los procesos de descentralización y de instrumentación de los presupuestos participativos (ANDREWS, 2003). Esta dimensión deliberativa (HABERMAS, 1997), se vincula estrechamente a la noción de: “ciudadanía ampliada o activa pensada como empowerment" (ARAUJO, 2006:163) y en relación con la consolidación política de órganos locales deliberantes, que promoverían los procesos de participación, “ampliando así el ejercicio de la ciudadanía” (ARAUJO, 2009:159).

Se indica que para las ciudades es un momento crítico (ídem), en términos de gestión, cambios y puntos de inflexión, lo que requiere el pasaje de estrategias centralizadoras a otras descentralizadoras, entendiéndose que existe: "la necesidad de conseguir formas de gobierno más efectivas, pues el deterioro del entorno urbano avanza rápidamente y las ciudades siguen vulnerables a los impactos macroeconómicos" (PAIVA, 2001: 2). Este proceso descentralizador implica también, entonces, una renovación del proyecto de identidad política ciudadana, frente a: "una crisis de las identidades colectivas y de participación en las instituciones representativas y en los partidos políticos" (BORJA, 1997: 90).

La ciudad es así percibida como un referente político crucial que replantea el debate sobre la democracia: "los gobiernos metropolitanos deben entenderse más como consorcios que como relaciones jerárquicas" (PAIVA, 2001:9); discutiéndose la ciudad como un espacio público abierto, garante de la integración social (BORJA, 1997) protectora de derechos y del progreso social (BORJA, 2003). Como se puede percibir es una perspectiva que amplía la visión integrativa e integradora, nucleadora y optimista de una cultura urbana cívica e incluyente (FISHER, 1996). Recalco lo de "incluyente", pues está implícita la idea de que existe la posibilidad -como ya indiqué- de que todos tienen o pueden tener un lugar en el espacio y la geografía urbana: “Una ciudad competitiva debe tener capacidad de integrar, en términos socioculturales, a la gran mayoría de su población" (BORJA, 1997: 85). Igualmente Preteceille (1996) gusta de describir a la pequeña ciudad como "más armoniosa, con tejido social más unido" (ídem. p. 22), dentro de una renovación de un proyecto generoso de la cultura urbana desde una vertiente integradora y nucleadora, que posibilita identidad y sentimiento de pertenencia a sus habitantes. 
Se enumeran así una serie de factores que favorecerían al espacio urbano como promotor de la renovación ciudadana, compensando las crisis globalizadoras que atrasarían: "la emergencia de las ciudades como protagonistas" (FISHER, 1996: 81): la velocidad de la información sobre mercados internacionales y la adaptación a los mismos, la flexibilidad de las estructuras productivas y la capacidad de insertarse en redes, las riquezas naturales y la situación geográfica (FISHER, 1996). Preteceille señala algo parecido: "las lecturas diferentes que son hechas de esa mutación económica concuerdan en reconocer una ventaja y una posición específica para las mayores ciudades" (PRETECEILLE, 1996: 15).

De acuerdo a estos análisis los factores económicos, geográficos e históricos negativos globales no lograrían superar la capacidad de adaptación y modernización de la ciudad en tanto se lleve adelante una cultura que aliente liderazgos participativos, dentro de una profundización de la democracia y del proyecto de ciudadanía. Esta cultura urbana brinda, incentiva, genera oportunidades, dentro de un florecimiento de la cultura de ciudadanía y de la cultura de lo racional. No en vano se enfatiza tanto el papel de la planificación, la coordinación, lo presupuestario: “El valor estratégico de la acción coordinada dentro de la metrópoli es considerado en los planes de desarrollo urbano, en la formulación de planes de desarrollo de infraestructuras y en los programas de desarrollo y estímulo económico" (PAIVA, 2001:10)

Es interesante observar que en la medida en que los autores re-definen este espacio urbano amplio y generoso, se vuelve a destacar uno de los ejes que se podría considerar fundamental del modelo keynesiana: la oportunidad ciudadana dentro de un sentido de porvenir (KLEIN, 2006). Se desarrolla pues el sentido de una cultura urbana con función unificadora que descansa en el ideal de diálogo y en la resolución de conflictos, teniendo como marco de referencia ineludible un proyecto de ciudadanía al que se considera totalmente vigente.

\section{LA CULTURA URBANA PARTICIPATIVA, DESCENTRALIZADORA Y LA PROBLEMÁTICA DE LA AUTORIDAD.}

Podría suponerse, desde esta óptica, que la ciudad no es un ámbito que por si mismo genere crisis sociales (lo que se ubicarían a nivel global), sino que aparece como un espacio político-social de búsqueda de soluciones a las mismas, a través de un: "nuevo paradigma de la relación entre las administraciones públicas" (FISHER, 1996: 88), lo que se presenta como reforma política radical (ídem: 86). En Latinoamérica, se revaloriza dentro de este proceso, el papel de los gobiernos locales a través de la política de descentralización (ARAUJO, 2006). 
Se destaca junto a la participación ciudadana la figura institucional del prefecto de la ciudad. Se indica que cuando las ciudades pierden oportunidades históricas, no pocas veces se debe al liderazgo disfuncional de sus prefectos (BORJA, 1997), lo que parece una acentuación de una figura política "tradicional" o "vertical" en el mismo momento en que se busca valorizar la democracia deliberativa. La necesidad de su figura replantea así el lugar y la función de la autoridad frente a la insistencia de la necesidad de participación, en tanto: "derecho de actuar en todos los campos de intereses general de la ciudadanía" (FISHER, 1996: 87).

En la figura del prefecto se solidifica un aspecto de esta cultura urbana participativa, en tanto se discute la posibilidad de un liderazgo conjunto y participativo desde el proceso de descentralización. Por otro lado, se indica que este tipo de liderazgo no descarta sin embargo aspectos carismáticos (BORJA, 1997), pues se entiende que representa la ciudad y hasta cierto punto es la ciudad (al menos desde el marketing) (ídem).

Se desliza así un doble entrecruce: el del prefecto con un liderazgo participativo y el de los habitantes de la ciudad, como ciudadanos capaces de intervenir a distintos niveles, más allá de diferencias de clase u otras, lo que aparecería como facilitando el proceso de convivencia democratizante (PIRES DO RIO CALDEIRA, 2000). De esta manera en la gran ciudad se estimula: "la movilidad espacial y social, ofreciendo más recursos para que ella se realice..." (PRETECEILLE, 1996: 37), indicándose que las clases dominantes pueden menos fácilmente construir una dominación política fundada en una actitud excluyente (ídem).

De esta manera la doble dimensión política que se entrecruza entre la figura del prefecto (más vertical) y la figura ciudadana (más horizontal) se subsume positivamente en una dialéctica de innovación y conflicto entre ambos aspectos, que enriquecería y complejizaría el proceso de descentralización participativa: "habría más capacidad de innovación en una gobernabilidad fundada en el conflicto (...) que en una gobernación fundada en la hegemonía, más unificada" (ídem: 37).

Esta perspectiva parece indicar una matriz de cultura urbana fuertemente asentada en la posibilidad de cohesión social, donde el problema de la diferencia (entre clases sociales, entre el prefecto y los habitantes de la ciudad, entre lo local y lo global) se puede subsumir desde la cultura de la igualdad de ciudadanía, la oportunidad de participación, y el enfoque descentralizado. Este acento puesto en la importancia de lo cohesivo y de identidad mutua, parece recordar la descripción de cultura urbana integradora en el sentido de la Gemeinschaft (tal como señala Tönnies) en la Gesellschaft (NISBET, 1996). Sin embargo, hay que indicar, al mismo tiempo, la 
importancia que se otorga al valor de la diferencia, lo ajeno, lo divergente, dentro de una perspectiva pos-moderna (BAUMAN, 1988) que también impregna esta cultura urbana participativa.

La ciudad pasa a ser, desde este modelo, una articuladora, una mediadora de posibilidades, dentro de un modelo de regulaciones. El núcleo de sus posibilidades de regulación estriba en el desafío del diálogo, como extensión de una política racional, con predominio de la comprensión y la búsqueda positiva de resultados. Lo que Preteceille (1996) presenta como optimización del conflicto. En tanto matriz de intercambio, se impone la idea de cierta igualdad, aún en la diferencia, representado emblemáticamente en la importancia de la figura del prefecto, que aparece revestido de rasgos carismáticos que no descartan otros de cuidado y protección.

\section{LA CULTURA URBANA COMO MATRIZ EXCLUYENTE}

Desde el proceso que inaugura el neoliberalismo (y probablemente, en especial el latinoamericano) comienzan a surgir o agregarse modificaciones substanciales al modelo anterior. La dinámica urbana se va volviendo inseparable de procesos (JUNGEMANN, 1996) que conllevan progresivamente la consolidación de:

Una sociedad heterogénea y fragmentada, surcada por profundas desigualdades de todo tipo- clase, etnia, género, religión, etc.- (...) hay un amplio sector social, un tercio excluido y fatalmente condenado a la marginación y que no puede ser "reconvertido" laboralmente ni insertarse en los mercados de trabajo formales (...) se traduce en desempleo masivo, pobreza extrema, anomia y desintegración social, drogadicción y auge de la criminalidad (SADER, 1999:80-81).

Uno de los factores principales que hacen a la matriz económica del neoliberalismo es la predominancia del Mercado (VASCONCELOS Y MORGADO, 2005), el que aparece regulado por fuerzas anónimas e invisibles que hacen que los acontecimientos parezcan producto del caos o el azar y no de factores racionales. Vale decir: los acontecimientos se presentan como un instituido incambiable. Aquél proyecto del modelo keynesiana de una sociedad integrada por seres autónomos y racionales, mediados por el planeamiento público nacional, se substituye por una fantástica utopía de una sociedad donde no entran ni regulaciones, ni leyes ni diferencias a título de una globalización en Red (DOFOUR, 2005).

Lewkowicz (2004) denomina "estado de fluido" a esta pérdida de referentes "sólidos" que sostiene un mercado de circulación ininterrumpida e ininterrumpible, aún al precio de una ruptura 
social (SADER, 1999). Este mercado si por algo aparece caracterizado, es por "fuerzas" autorreguladas, exigiendo una hiperadaptación a su dinámica (FORRESTER, 2000). Pasa a asemejarse casi, desde el imaginario social, a una Máquina donde todo está programado, previsto (ANZIEU, 1986) y "naturalizado". Las leyes del mercado de esta manera aparecen como eficaces e inmutables. Ya no son creación de los hombres, por el que entre la sociedad y sus integrantes se instala una nueva geografía (social y psíquica) de desconocimiento (SASSEN, 1988) y no de inclusión.

La cultura urbana pierde rasgos de seguridad y confianza, y adquiere otros de miedo y recelo:

La ciudad se ha vuelto definitivamente peligrosa, generando una inseguridad que surge de la irremediable pérdida de un paraíso que ya no nos pertenece, así como de una organización espacial fruto de nuestros miedos. La inseguridad no es la única causa de esta peligrosidad. Los índices de delincuencia no son suficientes para explicar el incremento de la inseguridad (BOISTEAU, 2007: 39).

Efectivamente, como indica Boisteau, no se trata solo de la figura del delincuente, sino probablemente de una mutación más radical en relación a la concepción del Otro. La figura del "vecino-ciudadano" es substituida por la del "extraño-ajeno", revestido con características de amenaza, indefinibilidad y des-responsabilización social (BAUMAN, 1999).

De esta manera el diálogo político (en su sentido cívico) que implica un marco de confianza, es substituido o aparece acompañado cada vez más, por las figuras del miedo y la desconfianza. Jordi Borja indica certeramente: “Un fantasma recorre Europa (y el mundo desarrollado en general), el fantasma del miedo, el miedo al otro, a los distintos, a los que no nos gustan, a los que de una forma u otra expresan realidades que no queremos ver" (BORJA, 1997:58).

La ciudad toma desde aquí otra acepción: ya no convoca sino que excluye. Esta situación que incrementa lo paranoico, corroe la "confianza" como metaorganizador de las relaciones sociales y excluye, aparece entonces con rasgos tanáticos (LAPLANCHE-PONTALIS, 1981) en el sentido de que "rompe" el lazo de integración, inclusión social y participación de sus habitantes.

Sassen (1988) señala cómo la economía global, no está para nada difuminada a través de la telemática o lo espacial, sino que requiere de puntos de concentración de propiedad, control y asignación de utilidades (ídem: 13). Esta hipermovilidad y liquidez del capital, que se completan con marginalidad y exclusión, se desarrolla dentro de una forma de cultura basada en la fuerte dislocación de identidades, territorios y pertenencias: “...tiene el efecto de excluir una variedad de procesos globales que se refieren realmente a la re-territorialización de gente, de prácticas económicas, de cultura" (ídem, 15). Una consecuencia de este proceso es que se: "agudizan las fracturas socioespaciales" (GIL BEUF, 2009:1). 


\section{LAS CIUDADES PERCIBIDAS COMO DIVISIÓN, DESCONOCIMIENTO, SEGREGACIÓN.}

De esta manera junto a una matriz cultural de inclusión y oportunidad, pasa a coexistir otra, de exclusión y marginalidad urbana. Preteceille señala cómo las grandes ciudades están profundamente divididas, no solo en términos espaciales, sino también en términos de clases sociales: "El análisis panorámico de los resultados empíricos ciertamente mostró la amplitud de las divisiones sociales en aquellas ciudades y la intensidad de los procesos que las reproducen y las transforman" (PRETECEILLE 1996: 33). Laura Tavares relaciona estas fracturas sociales, espaciales y culturales a la incidencia del neoliberalismo, que en el caso latinoamericano no se limita a: "medidas económicas de efectos coyunturales y /o transitorias... [sino que trae]... consecuencias sociales graves y permanente, muchas veces de difícil vuelta atrás" (TAVARES, 1999: 171).

Desde estos datos es posible entender que es inevitable que los ajustes económicos se tornen recesivos: "El Ilamado ajuste fiscal permanente trae un enorme costo para el sector público, con corte de gastos esenciales y desequilibrio patrimonial permanente" (ídem: 172). Paralelamente surge una "descentralización destructiva", donde se desmontan programas sociales, "sin dejar nada en substitución" (CORRÊA DO LAGO, 2001: 177). Punto que se entronca seguramente a que: "según la concepción neoliberal de política social, el bienestar social pertenece al ámbito privado" (ídem: 181). El predominio de la lógica neoliberal refuerza estos contrastes, ya que: "obliga a los gobiernos a privilegiar las políticas de competitividad sobre las políticas de reducción de las desigualdades y entonces a concentrar los esfuerzos sobre los espacios productivos" (GIL BEUF, 2009:7).

La segregación es una de las formas que va tomando este tipo de cultura urbana en relación a estas políticas de desempleo, reajuste y recesión, pero también frente al tema del miedo, la paranoia y la inseguridad. Se constata así que: "En América Latina, las nuevas policentralidades surgen en el contexto de urbes altamente segregadas social y espacialmente. Se insertan en los territorios periféricos, pericentrales e incluso centrales o se implantan en las zonas de expansión de las ciudades" (GIL BEUF, 2009:1). Luciana Corrêa do Lago (2001) señala cómo existe una lógica segregadora general que abarca a los distintos grupos sociales y en general a los vínculos intersubjetivos. La estructura jerárquica se transforma en una estructura espacial-territorial, que tiende a prolongarse en el tiempo, sin que sea posible: "alterar la posición del área en la jerarquía socio-espacial de la metrópolis, o sea, de alterar el tipo socio-espacial del área" (CORRÊA DO LAGO, 
2001: 171). Cabe señalar entonces, que la segregación alude no sólo a una repartición geográfica sino que involucra a una matriz social y a un tipo de cultura urbana.

\title{
LA CULTURA URBANA DEL ENCLAVE FORTIFICADO
}

Es importante indicar que esta cultura urbana de segregación y exclusión no se aplica sólo a las clases más desfavorecidas social y económicamente (enfoque que ciertamente es el tradicional), sino que atraviesa también a las clases con más riqueza, aunque se manifiesta de forma diferente. A una: "fuertísima concentración de riqueza" (PRETECEILLE, 1996: 22)3, se le acompaña simultáneamente de una cultura de "auto-segregación" (ídem: 29), y de auto-enclaustramiento, con preferencia por el: "espacio protegido, custodiado por policías privados y cercados con alambres" (ídem: 30), consolidando lo que en Latinoamérica se denominan: "enclaves fortificados":

\begin{abstract}
Sobrepuestas al padrón centro-periferia, las transformaciones recientes están generando espacios en los cuales los diferentes grupos sociales están muchas veces próximos, pero están separados por muros y tecnologías de seguridad y tienden a no circular o interactuar en áreas comunes. El principal instrumento de ese nuevo padrón de segregación espacial es lo que llamo "enclaves fortificados". Trátase de espacios privatizados, cerrados y monitoreados para residencia, consumo, placer y trabajo. Su principal justificación es el miedo al crimen violento (PIRES DO RIO CALDEIRA, 2000: 211).
\end{abstract}

Otros autores prefieren el término guettización: "Las distancias sociales han aumentado y los ricos tienden a aislarse cada vez más del mundo extraño e inquietante de los desposeídos. Los guettos fortificados de los ricos son testimonio del abismo que los separa de buena parte de la población de sus países" (O’DONNELL, 1999: 79).

Estos procesos de segregación se correlacionan asimismo, más allá de sus aspectos políticos y económicos, con la consolidación progresiva de una cultura que favorece la endogamización social y la generación de espacios de desagregación radicales, buscando una distancia (que no deja de tener aspectos paranoicos) con todo aquello "distinto" cargado ahora con el sentido de lo "persecutorio" y "disruptivo". Esta situación se acompaña de la valorización (sentida como extrema necesidad) de un proceso de homogeneización social notable: "Ios enclaves tienden a ser ambientes sociales homogéneos (...) cultivan un relacionamiento de negación y ruptura con el resto de la

\footnotetext{
${ }^{3}$ El autor se refiere a ciudades europeas, aquí se generaliza a Latinoamérica.
} 
ciudad..." (PIRES DO RIO CALDEIRA, 2000: 258-259)4. Es necesario destacar que esta segregación tiene que ver también con el status en tanto valor cultural: "están transformando sus casas en prisiones, pero sus prisiones dicen mucho sobre su posición social” (ídem: 297).

La segregación de las clases favorecidas parece tener como base común la idea -implícita- de una cultura urbana excluyente basada en la recreación de una microsociedad. Es decir, se trata, en mayor o menor grado, de la consolidación de una utopía, a través de la cual se busca concretar un espacio de homogeneización que permita la sensación de un control permanente. Esta situación: "ayuda a mantener el condominio como un mundo homogéneo y aislado. El control completa el 'nuevo concepto de vivienda', esto es, la imagen de un mundo exclusivo, aislado, disciplinado, fortificado, homogéneo y auto-suficiente..." (idem: 272). Se retomará este punto en las conclusiones en relación a la temática del miedo social.

\section{LA CULTURA URBANA EXCLUYENTE FAVELIZADA}

Para las clases más desamparados esta cultura segregatoria implica que se generan: "un sinnúmero de nuevas formas de exclusión social, en la medida en que empeoró las condiciones de empleo y trabajo (...) y creó un desempleo cuya dimensión supera cualquier otra marca histórica ya vista en Brasil "[y se podría agregar, en Latinoamérica] (CORRÊA DO LAGO, 2001: 174). Preteceille por su parte señala que: "un nuevo proletariado terciario con empleos frecuentemente precarios substituye en parte un proletariado industrial" (PRETECEILLE, 1996: 20).

Se afirma así que: "han aparecido nuevas formas de pobreza y desigualdades" (BOISTEAU, 2007:8). Corrêa do Lago indica que: “dos fenómenos deben ser destacados [dentro de la lógica segregadora de la metrópoli brasileña]: (I) la pérdida de la capacidad de endeudamiento, reduciendo el acceso a la vivienda por el alquiler y por la compra con financiamiento a largo plazo y (II) el aumento del precio del transporte en el presupuesto familiar" (CORRÊA DO LAGO, 2002: 158). Estas condiciones socio-económicas centralizadas alrededor del fenómeno del desempleo

\footnotetext{
${ }^{4}$ Es sorprendente la homología de los actuales enclaves ricos con la descripción que hace Fritz Lang, en la película "Metrópolis" (1924), de una ciudad autosuficiente y subterránea de ricos. En este caso, la metrópolis actual está en la superficie de la tierra, pero conserva igualmente su status de confinamiento y segregación.
} 
estructural solidifican de esta manera una situación de indigencia, ya por muy por debajo de la línea de pobreza.

En el caso específico de la segregación favelizada, es necesario señalar que mientras el municipio de Río no aumenta su crecimiento poblacional, las favelas sí lo hacen, representando aproximadamente el 17\% de la población total (CORRÊA DO LAGO, 2002: 166). La favela y su crecimiento se explica -entre otros factores- por ser: "la única alternativa de vivienda para los que están precariamente insertos en la economía urbana y donde la proximidad con el mercado de trabajo, especialmente de prestación de servicios y construcción civil, es condición para su inserción" (ídem. 173).

De esta manera la segregación de las clases más desamparadas se va nucleando alrededor de favelas, pero también alrededor de villas miserias, barrios periféricos, en el centro de la ciudad o en su extremo- manifestándose como grupos de pobres deambulando por la ciudad. Pero, como en el caso de las clases más favorecidas, esta segregación no se debe sólo a factores sociales y económicos, sino que se entronca a una cultura urbana donde se va consolidando la categoría del "extraño-indeseable-perturbador", categoría ocupada por una diversidad de sujetos:

las autoridades locales, operan en masa en los centros históricos de sus ciudades. Empiezan por "limpiar" los centros de los pobres, indigentes e indeseables. Suele ser el vagabundo, el extranjero o el desplazado quien es visto como indeseable y amenazante, como si fuera el portador de patologías sociales y perturbador del sistema organizador (BOISTEAU, 2007:12).

El sujeto pobre es una de sus manifestaciones, pero de ninguna manera la única. Como señala Boisteau lo "amenazante" implica un clima general urbano donde las fronteras de la tolerancia y la comprensión se "achican" o se redefinen, alrededor de parámetros nuevos de cotidianeidad, en relación a lo que enseguida presentaré como estigmatización de lo indeseable.

\section{CONFINAMIENTO FORTIFICADO- ESTIGMATIZACIÓN DE LO INDESEABLE}

Tomando en cuenta los dos aspectos de la cultura urbana segregadora en lo que refiere a las clases favorecidas (confinamiento fortificado) y las clases en situación de indigencia (favelización ${ }^{5}$ o estigmatización de lo indeseable) se podría decir que mientras el confinamiento fortificado da un

\footnotetext{
${ }^{5}$ Cabe aclarar que el término: "favelización" genera la idea de una concentración espacial que no siempre se verifica. Como ya se indicó, en sus grados extremos la pobreza se presenta como deambulando por distintos puntos de la ciudad, constituida en una especie de tribu urbana.
} 
nuevo sentido a lo privado (inaccesibilidad e invisibilidad; entre el adentro y el mundo de afuera-lo público- se consolidan contenedores varios: policía, guardias de seguridad, muros, rejas, porteros, porteros eléctricos) la segregación estigmatizante resignifica el sentido de lo público (periódicos allanamientos, cateos, invasión policíaca y de la media, traslados forzados o semiforzados a refugios, expulsiones del centro o calles de la ciudad).

Habría que profundizar aún más esta hipótesis, pues probablemente estigmatización y confinamiento presentan como vector común la profundización del proceso paradojal de aislamiento -compartimentalizado: clases sociales espacialmente más próximas que nunca, tanto como simbólicamente más lejanas que nunca ${ }^{6}$. Por otro lado, la bibliografía consultada no da cuenta de lo que sucede con la clase media, tema de fundamental importancia y que merece investigaciones específicas.

Hay que precisar que la segregación confinante es electiva, y busca la "protección". Remite, se explicite o no, a una cultura de lo paranoico. Policías, cercas y alarmas se imponen cuando un grupo urbano se siente amenazado de ser atacado, desposeído o violentado por otro grupo urbano. Se impone un sentido de peligro y de lo catastrófico, en relación probablemente a una especie de "guerra civil" de baja intensidad y nunca declarada en su carácter de tal.

Por el contrario la segregación estigmatizante remite a un empuje, a una expulsión, que se renueva permanente y $\sin$ que aparezcan detrás de la misma motivos racionales, planificadores $u$ otros. Son motivos que están decididos siempre desde 'afuera', desde una imposición que toma no pocas veces la forma de una acción violenta.

\section{LA VIOLENCIA URBANA: ENCRUCIJADA E ILEGALIDAD}

Una de las expresiones de la cultura urbana excluyente se relaciona a la violencia. Para Pretecielle: “En el siglo XX (...) el grito de barbarie retornó a las representaciones de la gran metrópolis, la violencia social vuelve manifiesta las desigualdades, la destrucción del tejido social y la exclusión que caracterizan determinados suburbios" (PRETECIELLE, 1996: 16).

Sin poder realizar un estudio exhaustivo del tema, la perspectiva que se sugiere es que la violencia urbana no surge estrictamente de los factores de desagregación, marginación y exclusión, como si se tratara de un esquema mecanicista causa-efecto. A la misma sin duda se asocian factores sociales

\footnotetext{
${ }^{6}$ Como simple ejemplo, en la ciudad de San Pablo, en el mismo centro de uno de los barrio más adinerados de la ciudad - Morumbí - se alza una favela: Paraisópolis...
} 
y económicos innegables, favorecidos muchas veces, como ya se indicó por gestiones neoliberales recesivas y segregadoras. Pero por otro lado aparecen aspectos culturales y simbólicos y nuevas formas de lo cotidiano y lo vincular que es necesario también tener en cuenta: "Muchos de los elementos que han generado el actual ciclo de violencia tiene una base socioeconómica. Entretanto (...) son insuficientes para explicar el aumento de formas privadas e ilegales de venganza y consecuentemente del aumento de la violencia" (PIRES DO RIO CALDEIRA, 2000: 207).

Se perfila de esta manera en el campo de la violencia urbana diferentes líneas de fuerza enfrentadas, conflictos irresolubles y paradojas varias; generando nudos complejos que son a veces ambiguos. Uno de ellos refiere al factor "miedo", el que se podría presentar como un factor común que atraviesa como vivencia, sensación o temor a todas las clases sociales urbanas (PIRES DO RIO CALDEIRA, 2000).

Quisiera insistir en que no se trata solamente del miedo al crimen, sino que se relaciona al redimensionamiento de lo que es la percepción 'inmediata' del Otro, 'cotidianizado' bajo las formas de lo ominoso, lo persecutorio, lo angustiante. De esta manera las posibilidades de encuentro y comunicación se resienten, a favor del enfrentamiento, el recelo y la inseguridad (KLEIN, 2006). Lo que lleva, como ya se indicó, a una política de enmuramiento de condominios y viviendas, en relación a vivencias de desamparo y de supuesta "impotencia" de los aparatos judiciales o policiales por contener situaciones de peligro inminente (ídem).

En su límite quizás sea miedo a algo que no se puede terminar de definir ni de pensar ni de comprender totalmente. Pero cuánto más vago se vuelve este miedo más genera, en su nombre implícita o explícitamente- decisiones y estrategias urbanas muchas veces represivas:

hemos entrado en una época en la que las decisiones urbanísticas, políticas, económicas y sociales se toman bajo la influencia del miedo: un miedo más creado que real, un miedo colectivo que influye en las decisiones de planificación y moldea, por mucho tiempo, los lugares dónde vivimos (BOISTEAU, 2007:8).

Una de sus características apunta a que algo malo y horrendo puede pasar en cualquier momento y lugar, lo que se podría englobar como: "sensación de catástrofe inminente" (KLEIN, 2006) que también se asocia a la vivencia del descontrol, el desborde de la "caótico", y lo anárquico, asociado a lo "pobre", el "extranjero", el "imigrante" o el "desajustado" social.

Si en la cultura urbana integradora la violencia aparece como un "accidente" sobre un fondo de convivencia dialógica, en la cultura urbana expulsiva la misma va adquiriendo otra dimensión. Paulatinamente se la erige como instrumento adecuado para la solución de problemas y conflictos 
urbanos sociales. Esta violencia "correctiva" se va incorporando como algo rutinario, necesario y aceptado en lo cotidiano de la cultura urbana:

La Folha de S. Paulo, publicó... (una)... investigación de opinión apoyando la política de seguridad pública (...) $71,8 \%$ de las personas entrevistadas declararon que la política de seguridad pública debería ser 'más dura' en el combate a la criminalidad. Más dura significa más violenta (PIRES DO RIO CALDEIRA, 2000: 170).

Es obvio que esta violencia usada como instrumento de seguridad pública implica un retroceso de derechos civiles y hasta políticos y sociales, pero eso no impide que cada vez más se haga de la misma un recurso "mesiánico" para resolver problemas urbanos y sociales.

Se trata de una violencia muchas veces descarnada, que pierde todo elemento estructural de posible regulación (LEWKOWICZ, 2004), para pasar a ser un franco elemento de represión. Tiene que ver entonces con la entronización de la violencia como ideología triunfante, cargada con la expectativa de sus posibilidades transformadoras y reguladoras de la sociedad. De esta manera, la resistencia a las reformas en contra de la brutalidad policial "vienen no sólo de la policía, sino también de la población y de la media" (ídem: 179), imponiéndose progresivamente, sin poder discriminarla ni cuestionarla, una geografía de la violencia por la violencia misma. Tanto temida como buscada, tanto como se es víctima como empuñador de la misma, se termina por convertir, al mismo tiempo, en la explicación y en el remedio de los problemas sociales, en el convencimiento de que los problemas sociales ya no se pueden solucionar con políticas sociales.

Esta "mesianización" de la violencia, es inseparable por tanto, de una perspectiva cultural que ya no considera posible que las cuestiones sociales se resuelvan social o jurídicamente: "Las reacciones de todos los grupos sociales a experiencias cotidianas como la violencia y como instituciones de orden ineficaces parecen estar llevando a una deslegitimización del estado de derecho" (PIRES DO RIO CALDEIRA, 2000: 135). Una consecuencia es la renovación de la idealización de la fuerza y la violencia como reguladores admitidos de las tensiones sociales, junto al descreimiento en el aparato judicial y en la ley como reguladores sociales (PELLEGRINO, 1987) y junto a la consolidación del modelo de "criminalización” de la pobreza (GRYNER, 2003), (RODRÍGUEZ, 2003).

En el caso latinoamericano este tipo de violencia, parece que continúa modelos provenientes de las dictaduras o gobiernos de fuerza que asolaron a la región (PIRES DO RíO CALDEIRA, 2000). Esta situación implica la transmisión social y cultural de determinadas pactos (PUGET-KAËS, 1991), en relación a la conservación de contenidos sociales y culturales (TISSERON, 1995) que se vinculan, entre otros factores, a la supervivencia de situaciones de impunidad que revelan la ineficacia judicial 
(y política) en procesar violaciones de los derechos humanos que quedan en situación de irresolución permanente (ENRIQUEZ, 2000).

Es posible pensar asimismo que este modelo de violencia urbana desarticula determinados fundamentos del conjunto social (PUGET-KAËS, 1991). Una de esas formaciones es la cultura de diálogo, substituida por una estructura donde los espacios sociales se achican y se vuelven intolerantes, lo que lleva a que se "apriete" el espacio entre los hombres, como señala Hanna Arendt (GÓMEZ RAMOS, 2003). Al mismo tiempo - como ya se indicó- la figura del vecino es substituida por la del "extraño" (BAUMAN, 1999), corroyéndose la "confianza" en el Otro, como metaorganizador de las relaciones sociales.

\section{CONCLUSIONES}

La cultura urbana es compleja, heterogénea, altamente transversalizada y admite sin duda diferentes lecturas. Cuando se eligió como eje de análisis la ciudad integradora junto a un modelo de ciudad excluyente no se pretendía hacerlo desde perspectivas antinómicas, sino por lo menos confluentes. Si el espacio democratizador de la ciudad alterna y se yuxtapone al espacio represor y controlador de la misma, sin que esta dualidad genere desconcierto o estupor, es posible indicar ciertamente el: "carácter paradojal de una sociedad en que instituciones democráticas y prácticas represivas abusivas coexisten" (PIRES DO RIO CALDEIRA, 2000: 174).

Probablemente la ciudad encubre y recubre ambos aspectos, en tanto excluye tanto como integra, expulsa tanto como protege. Heredera y transformadora de diferentes discursos y prácticas, la cultura urbana los pone en práctica tanto como los cuestiona, cuando le es posible.

Desde los datos aportados precedentemente se podría indicar cómo junto a un modelo urbano inclusivo, coexiste otro expulsivo. El proyecto de cultura urbano integrador se apoya en un basamento racional, que se atiene a los valores de lo seguro, lo confiable y previsible. Por su parte, la cultura urbana expulsiva, se une a situaciones de guettización, confinamiento, estigmatización e inseguridad, entre otras. En el primer caso la ciudad aparece como un espacio unificador y unificado, mientras que en el segundo se perfila como una sumatoria de "guettos" heterogéneos. Esta disparidad no puede sino generar puntos de tensión ineludibles.

Se podría sintetizar estas apreciaciones y señalar como, culturalmente, la ciudad presenta dos grandes vertientes, en algunos momentos claramente distinguibles y en otros, complejamente entrelazados. Por un lado, aparece como lugar de protección, de resguardo, auspicio y creación de cultura. Su modelo es la 'hospitalidad' y el 'vecino'. Por otro, la ciudad sostiene las versiones del 
Otro como alguien ominoso, generando fantasías paranoicas de robo, destrucción y maldad. Su modelo es el 'enclaustramiento' y el 'extraño'. Desde aquí el miedo deviene articulador de las relaciones sociales y su consideración es fundamental, como se indicó, para el estudio de la violencia urbana.

Más allá de esta complejidad, parece importante indicar cómo algunas investigaciones parecen privilegiar sólo algunos de estos aspectos, sin poder integrarlos plenamente. Un ejemplo es el de la descentralización, que se presenta como uno de los ejes de la ciudad, en tanto integradora y promotora de ciudadanía deliberante. Sin embargo, y al mismo tiempo, el convencimiento de su importancia estratégica renovadora no es obstáculo para que se le retaceen crónicamente recursos que le son esenciales, (PAIVA, 2001), (STEPAN, 2002) lo que ha condicionado y hasta vulnerabilizado algunos de los objetivos de la misma (AZEVEDO, 1997).

De esta manera la descentralización no solo no ha podido cumplir totalmente con las funciones esperanzadoras que se le atribuyeron o atribuyen, sino que ha generado - en algunos casosresultados o situaciones muchas veces imprevisibles y supuestamente incompatibles con la descentralización misma. Uno de ellos refiere al incentivo de los procesos de fragmentación: "la proliferación de gobiernos locales dentro de las ciudades, siguiendo el argumento de la representatividad, ha producido ciudades fragmentadas, con consecuencias en la eficiencia de la prestación de servicios públicos" (PAIVA, 2001:7). Otro factor se relaciona a su ubicación, no como política de mejor uso público, sino como estrategia de control urbano "para controlar mejor los territorios e intentar evitar el "desorden" urbano" (BOISTEAU, 2007:12).

Finalmente cabe pensarse si la descentralización no se relaciona también con posible incremento de intolerancia, pues: "Los lazos de confianza y solidaridad pueden también crear capital social negativo, como es el caso de comunidades muy cerradas que acaban creando espacios de intolerancia y discriminación" (ARAUJO, 2006:165- nota a pie de página).

Como se advertirá todas estas situaciones emergentes desde la descentralización se podrían asociar mejor al modelo de la ciudad excluyente, lo que podría hacer pensar de vuelta, en la complejidad, entrecruce y alta ambigüedad de los fenómenos y las culturas urbanas, más allá de idealizaciones varias (la descentralización en un caso, la violencia represiva en otro). Otra de estas idealizaciones (que no es posible desarrollar aquí) corresponde al concepto de planificación urbana. El término mismo "planificación" genera la sensación de un caos urbano que ha de ser "ordenado" y "civilizado". Más que la solución de un problema, parece implicar entonces el diagnóstico de un problema. 
Se ha mencionado al uso de la violencia como factor de regulación social que recibe un importante respaldo cultural actualmente, a pesar de que genera situaciones de regresión tanto social como subjetiva, con consolidación de modelos de fuerza por fuera del espacio democrático y dialógico.

Esta situación (la violencia y el miedo correlacionado) debería ser uno de los principales temas a discutir y debatir dentro de cualquier agenda de renovación cultural urbana. Especialmente llama la atención cómo el miedo aparece actualmente articulado férreamente con el tema de la llamada inseguridad ciudadana. Las personas en las ciudades sienten miedo, se sienten "inseguras" y esta inseguridad opera como autorizador de políticas que incentivan -sin embargo- aún más, el miedo y la inseguridad.

Jordi Borja acertadamente analiza en tal sentido la Ordenanza del Civismo aplicada en el año 2005 en la ciudad de Barcelona, mezcla de represión y educación, control y denuncia que termina por desmoralizar aquello que supuestamente se pretende moralizar (ídem: 11).

El referido autor llega a hablar, acertadamente, de la instigación de prácticas de denuncia y delación. Sin duda, nada más alejado de una filosofía democrática y ciudadana, en nombre (contradictoriamente) de una filosofía democrática y ciudadana...Una nueva paradoja por la cual se des-ciudadanizan estructuras dialógicas fundamentales que se suponen son imprescindibles para el desarrollo de la democracia urbana. En nombre de la seguridad las ciudades terminan por generar en realidad una cultura de incremento del miedo y la inseguridad.

Desde esta cultura de la inseguridad, que aparece como urgente "combatir", las ciudades pasan (en diversos grados) por procesos de militarización (transitorios o crónicos) con incremento de las políticas de control. La misma metáfora del "combatir", parece justificar aspectos del uso de la fuerza, militarización y políticas de control que se van naturalizando cada vez más en la cultura urbana.

Al mismo tiempo, se insiste en la necesidad de la participación ciudadana, pero parece difícil que la misma se pueda consolidar si no es desde condiciones que aseguren confianza básica. Dicho de otra manera: parece difícil que pueda subsistir como figura de cultura urbana un modelo jurídicodeliberativo-inclusivo, mientras el discurso urbano se estructura hegemónicamente desde un modelo paranoico-violento-expulsivo. Una alternativa, quizás, son los vaivenes entre procesos de ciudadanización y des-ciudadanización. Los dobles discursos por los que pasa el modelo de descentralización, quizás dan cuenta justamente de esta realidad que se hace necesario indagar, 
abriendo un debate en torno a las prácticas y las posibilidades integradoras- excluyentes actuales de la cultura urbana.-

\section{BIBLIOGRAFÍA}

ANDREWS, Charles. Reificação e Legitimidade. Habermas como Metateoria das Policy Sciences. Universidade de São Paulo- Departamento de Ciência Política, 2003.

ANZIEU, Didier. El grupo y el inconsciente grupal. El imaginario grupal. Madrid: Biblioteca Nueva, 1986

ARAUJO, Ana (ed.) Impactos del desempleo. Transformaciones en la subjetividad. Montevideo:

Alternativas, 2002

ARAÚJO FERNANDES, Antônio; SOUZA BONFIM, Washington. La democratización de la gestión municipal en Brasil: un abordaje teórico del objeto. Disponible en:bibliotecavirtual.clacso.org.ar/ar/libros/edicion/diseno/araujo.pdf.

[Consulta: 10 diciembre 2018], 2006.

ARIÈS, Philippe; DUBY, George (eds.). La Comunidad, el Estado y la Familia, vol. VI: Historia de la vida privada. Buenos Aires: Taurus, 1990.

AULAGNIER, Piera. La violencia de la interpretación. Del pictograma al enunciado. Buenos Aires: Amorrortu, 1975

AZEVEDO, Sérgio. Políticas Públicas e Governança em Belo Horizonte. Brasil, Cadernos IPPUR, Rio de Janeiro, XI (1; 2), p. 63-74, 1997

BAUMAN, Zygmunt. Modernidade e Ambivalência. Rio de Janeiro: Jorge Zahar Editor, 1999. 
BAUMAN, Zygmunt. O Mal-estar da Pós-modernidade. Rio de Janeiro: Jorge Zahar Editor, 1998.

BECK, Ulrich. Modernización reflexiva-política, tradición y estética en el orden social moderno. Madrid: Alianza Universidad, 1997.

BIRMAN, Joel. Mal-estar na atualidade. Rio de Janeiro: Civilização Brasileira, 2001.

BLEICHMAR, Silvia. Acerca del malestar sobrante. Disponible en: www.topia.com.ar/aartículos/21malest.htm.

[Consulta: 10 diciembre 2009], 1997.

BOISTEAU, Charlotte (ed.) Políticas urbanas y convivencia en ciudades de América Latina. Hacia una gestión integral de la ciudad- Primer encuentro del Comité de Desarrollo de la Red Políticas Urbanas y Convivencia en las Ciudades de América Latina (CONVIVAL)-Chile, 2007.

BORJA, Jordi. Las ciudades y el planeamiento estratégico. Una reflexión europea y latinoamericana. Urbana, 22, p. 104-117. 1998

BORJA, Jordi. La Ciudad Conquistada. Madrid: Alianza Editorial. 2003

CASTEL, Robert. La metamorfosis de la cuestión social. Una crónica del salariado. Buenos Aires: Paidós, 1997

CORRÊA DO LAGO, Luciana. A lógica segregadora na metrópole brasileira: novas tesis sobre antigos processos. Cadernos IPPUR/UFRJ, ano XV, No. 2, ago. dez, p. 155-176 2002.

COUTINHO, Carlos. Contra a corrente- Ensaios sobre Democracia e Socialismo. São Paulo : Cortez, 2000

DUFOUR, Dany Robert. A arte de reduzir as cabeças. Sobre a nova servidão na sociedade ultraliberal. Rio de Janeiro: Companhia de Freud Editora, 2005. 
DUSCHATZKY, Silvia (ed.) Chicos en banda. Los caminos de la subjetividad en el declive de las instituciones. Buenos Aires: Paidós, 2002.

ENRIQUEZ, Enrique. El fanatismo religioso y político en: LEVI, André (ed) Psicosociología, análisis social e intervenção. Belo Horizonte: Auténtica, p. 10-21, 2001.

FISHER, Tânia. Gestão contemporânea, cidades estratégicas e organizações locais. Rio de Janeiro, Fundação Getúlio Vargas, 1996

FORRESTER, Viviane. Una extraña dictadura. Buenos Aires: Fondo de Cultura Económica, 2000.

FOUCAULT, Michel. La Tecnología Política de los individuos. En: Coleção Ditos \& Escritos V. Rio de Janeiro: Política Forense Universitaria, p. 120-135, 2012

FOUCAULT, Michel. La Ética del Cuidado de si como practica de libertad. En: Coleção Ditos \& Escritos V. Rio de Janeiro: Política Forense Universitaria, p. 134-142, 1988

FOUCAULT, Michel. Deux essais sur le sujet et le pouvoir. En: DREYFUS, Hubert; RABINOW, Paul (ed) Michel Foucault. Un parcours philosophique. Paris : Gallimard, p.297-321, 1984

FRANKEL, Jay. Explorando el concepto de Ferenczi de identificación con el agresor. Su rol en el trauma, la vida cotidiana y la relación terapéutica. Disponible en: www.aperturas.org/11frankel.html [Consulta: 10 diciembre 2018], 2002

FREUD, Sigmund. El malestar en la cultura, En: Obras completas. Vol. XXI Buenos Aires: Amorrortu, 1931

GAVIDIA, José. Housing and Land in Large Cities of Latin America. En: Hoshino, C. (ed.) Enhancing the Management of Metropolitan Living Environments in Latin America. Japón: United Nations Centre for Regional Development (UNCRD), 1994. 
GIDDENS, Anthony. Modernidad e Identidad del Yo. Madrid: Península, 1997

GIL BEUF, Alice. Policentralidades urbanas: entre competitividad y equidad territorial- Reflexiones a partir del caso bogotano Disponible en: egal2009.easyplanners.info/area05/5012_Alice_Gil_Beuf.doc

[Consulta: 10 diciembre 2018], 2009

GOMEZ RAMOS, Antonio. Totalitarismo, historia y banalidad del mal. España, Disponible en: www.uc3m.es/uc3m/dpto/HC/AGR/totalitarismo.html.

[Consulta: 10 diciembre 2018], 2003.

GRYNER, Simone (ed) Lugar de palavra. Rio de Janeiro: Núcleo de Atenção à Violência (NAV), 2003.

HABERMAS, Jurgën. Direito e democracia: entre facticidade e validade.

Rio de Janeiro: Tempo Brasileiro,1997.

INGRAM, Gregory. Patterns of Metropolitan Development: What Have We Learned? Urban Studies, 35 (7), p. 1019-1035, 1998.

JUNGEMANN, Beate. Desarrollo regional y descentralización en América Latina en el marco del ajuste: una relación con muchas interrogantes. Caracas: Cuadernos del CENDES, 13 (32), p. 61-95, 1996

KAËS, René. El grupo y el sujeto del grupo. Elementos para una teoría Psicoanalítica del Grupo. Buenos Aires: Amorrortu, 1993

KANCYPER, Luis. Resentimiento y Remordimiento- Estudio psicoanalítico. Buenos Aires: Paidós, 1992

KANCYPER, Luis. La confrontación Generacional. Buenos Aires: Paidós, 1997 
KLEIN, Alejandro. Adolescentes sin adolescencia: Reflexiones en torno a la construcción de subjetividad adolescente bajo el contexto neoliberal. Montevideo: Psicolibro- Universitario, 2006.

LAPLANCHE, Jean- PONTALIS; Jean Bertrand. Diccionario de Psicoanálisis. Madrid: Ed. Labor, 1981.

LEWKOWICZ, Ignacio. Pensar sin estado. La subjetividad en la era de la fluidez. Buenos Aires: Paidós, 2004.

MARGULIS, Mario (ed). La cultura de la noche. La vida nocturna de los jóvenes en Buenos Aires Buenos Aires: Ed. Biblos, 1997.

NEGRÓN, Marco. La productividad de los asentamientos humanos: Viejos dilemas y nuevas perspectivas. Revista Urbana, 22, p. 25-44, 1998.

NISBET, Robert. La formación del pensamiento sociológico, Vol. I y II. Buenos Aires: Amorrortu, 1996.

O’DONNELI, Guillermo. Pobreza y desigualdad en América Latina: algunas reflexiones políticas.En: O’DONNELL, Guillermo; TOKMAN, Víctor (eds.) Pobreza y desigualdad en América Latina: temas y nuevos desafíos. Buenos Aires: Paidós, p. 123-131, 1999.

PACHECO, Carlos. Charles Taylor: Una crítica comunitaria al liberalismo político. Disponible en: www.revistapolis.cl/6/dono.htm,.

[Consulta: 10 diciembre 2018], 2000.

PAIVA, Antonio. Panorama metropolitano en Latinoamérica: Argumentos para la gestión metropolitana. Revista Urbana, 6 (29), p. 59-67, 2001 
PELLEGRINO, Helio. Pacto edípico e pacto Social. Folha de S.Paulo, 347, (11), p. 9-11, 1983

PIRES DO RIO CALDEIRA, Teresa. Cidade de muros: Crime, segregação e cidadania em São Paulo, São Paulo: Editora 34, 2000

PRETECEILLE, Edmond. Segregação, Classes e Política na Grande Cidade. Cadernos IPPUR/UFRJ, ago-dez, vol. X, No. 2,p. 15-37, 1996.

PUGET, Janine; KAËS, René. Violencia de Estado y Psicoanálisis. Buenos Aires: Centro Editor de América Latina, 1991

PUTNAM, Robert. The Prosperous Community: Social Capital and Public Life.

Disponible en: The American Prospect, 13, p. 35-42, 1993

RODRIGUEZ, Esteban. Un puño sin brazo. ¿Seguridad ciudadana o criminalización de la multitud. En: RODRÍGUEZ, Esteban (ed) La criminalización de la protesta social La Plata: Ediciones Grupo La Grieta, p. 19 a 48, 2003.

RUIZ, Castor. Os labirintos do poder: o poder (do) simbólico e os modos de objetivação. Porto Alegre: Escritos Editora, 2004

SADER, Emir; GENTILI, Pablo (org). La trama del neoliberalismo. Mercado, crisis y exclusión social. Buenos Aires: Universitaria de Bs. As, 1999.

SASSEN, Saskia. Ciudades en la economía global: enfoques teóricos y metodológicos. Santiago de Chile: Revista URE, vol. XXIV, (71), p. 5-25, 1988.

STEPAN, Alfred. O Federalismo Descentralizado no Brasil: aproximando o governo dos cidadãos?. En: Leslie Bethell (ed.) Brasil: fardo do passado, promessa do futuro Rio de Janeiro: Civilização Brasileira, 2002. 
TAVARES, Laura. Os custos sócias do ajuste neoliberal no Brasil. En: SADER, Emir (ed) Seminario: EI ajuste estructural en América Latina. Costos sociales y alternativas, Buenos Aires: CLACSO, p. 171186,2001

TISSERON, Serge (ed). El psiquismo ante la prueba de las generaciones. Clínica del Fantasma. Buenos Aires: Amorrortu, 1997

VASCONCELOS, Eduardo; MORGADO, Rosana. Subsídios analíticos e metodológicos para a atuação no Sistema Único de Assistência Social (SUAS), e do Programa de Atendimento Integral à Família. Rio de Janeiro: PAIF/SAS/RJ., 2005

WEBER, Max. Economia e sociedade: fundamentos da sociologia compreensiva. Brasília: Editora Universidade de Brasília, 1998

Trabalho enviado em 22 de fevereiro de 2019

Aceito em $\mathbf{2 0}$ de abril de 2020 